\title{
Sexualidade, cultura e política: a trajetória da identidade homossexual masculina na antropologia brasileira*
}

\author{
Sérgio Carrara** \\ Júlio Assis Simões ${ }^{* * *}$
}

\begin{abstract}
Resumo
Nosso objetivo é explorar o modo pelo qual o "jeito" supostamente brasileiro de organizar as categorias ou identidades sexuais (especialmente em relação à homossexualidade masculina) vem sendo tematizado na antropologia desde finais dos anos 1970, transformando-se às vezes num eixo para a construção/manutenção de uma identidade nacional caracterizada como exótica, retardatária e "não-ocidental". Também traçamos paralelos entre dois momentos da reflexão sobre as relações entre sexualidade, cultura e política, procedendo a uma breve revisão de algumas contribuições teóricas e empíricas anteriores que antecipam problemas e conceituações centrais dos atuais estudos de sexualidade, relacionados à instabilidade/fluidez das identidades sexuais e à imbricação da sexualidade em relações de poder $e$ hierarquias sociais dinâmicas e contextuais.
\end{abstract}

Palavras-chave: Homossexualidade, Antropologia Brasileira, Identidades Sexuais, Identidade Nacional.

\footnotetext{
Recebido para publicação em abril de 2007, aceito em maio de 2007.

** Professor do Instituto de Medicina Social, Universidade do Estado do Rio de Janeiro/UERJ. carrara@ims.uerj.br

**** Professor do Departamento de Antropologia, Universidade de São Paulo/USP e pesquisador do Núcleo de Estudos de Gênero - Pagu/Unicamp. juliosimoes@uol.com.br 
Sexualidade, cultura e política

Sexuality, Culture and Politics:

the Journey of Male Homosexual Identity in Brazilian Anthropology

\begin{abstract}
Our aim is to inquire into the ways in which a presumed Brazilian "managing" of sexual categories or identities (mainly related to male homosexuality) has been conceived in anthropology since the end of the 1970, sometimes becoming an axis for building and maintaining a national identity characterized as exotic, backward and not pertaining to "the West". We also parallel two moments in the reflection about the links between sexuality, culture and politics, briefly reviewing some of early theoretical and empirical contributions that prefigure central concerns and conceptualizations in present sexuality studies which are related to instability and fluidity of sexual identities, as well as to the entanglement of sexuality with dynamic and contextual power relationships and social hierarchies.
\end{abstract}

Key Words: Homosexuality, Brazilian Anthropology, Sexual Identities, National Identity. 
Sérgio Carrara e Júlio Simões

Ao Professor Peter H. Fry

Em certo ponto de sua etnografia sobre o mundo das travestis em Salvador, o antropólogo Don Kulick analisa a relação que as informantes mantinham com seus namorados ou "maridos". Sua principal informante lhe dizia que, na verdade, o fato de as travestis "sustentarem" seus namorados com dinheiro $e$ presentes marcava o poder que elas exerciam sobre eles e não o contrário. Diferente do que poderia parecer a um observador desavisado, não eram as travestis as exploradas nessa relação. Ou, como escreve Kulick:

\begin{abstract}
Um estrangeiro, vindo de uma cultura em que as relações sexuais se baseiam supostamente em sentimentos recíprocos de amor e em esforços mútuos para a geração de renda e para a manutenção da casa, poderia ver facilmente no relato e na prática das travestis [que dizem manter seus companheiros por vontade própria] fantasias de poder que elas colocariam em ação para mascarar a dura realidade de estarem sendo exploradas por gigolôs interesseiros e manipuladores (Kulick, 1998:112, grifo nosso).
\end{abstract}

Embora as relações que as travestis mantêm com seus namorados e os significados atribuídos a tais relações sejam interessantes para a discussão sobre o caráter da dominação em relações estruturalmente assimétricas, o que mais chama a atenção nesse trecho é a comparação explícita da "cultura" do observador estrangeiro - e o "estrangeiro" aqui é sem dúvida o próprio etnógrafo - e a do observado. Ao falar da reciprocidade e igualitarismo da sua "cultura", Kulick estaria referindo-se um tanto frouxamente a determinados valores das classes médias urbanas européias (nesse caso, suecas) ou a uma cultura ocidental, individualista e moderna, da qual as travestis estariam excluídas? É difícil saber ao certo. Mas como, quando se trata do universo das relações homossexuais ou homoeróticas, o Brasil em 
Sexualidade, cultura e política

particular e a América Latina em geral têm sido sistematicamente descritos nesse tipo de literatura como não pertencentes ao mundo ocidental, a segunda hipótese nos parece a mais provável.

Se a brasilidade vem sendo construída há mais de um século com referência privilegiada à sexualidade ${ }^{1}$, não deve causar espanto que as vicissitudes do processo de construção $e$ reconstrução de uma identidade nacional se espelhem também nos estudos sobre a homossexualidade. Não pretendemos aqui proceder a uma análise exaustiva do conjunto de etnografias sobre homossexualidade masculina ou sobre o universo das travestis no país. Nosso objetivo é explorar o modo muito particular pelo qual o "jeito" supostamente brasileiro de organizar as categorias ou identidades sócio-sexuais vem sendo tematizado desde finais dos anos 1970, transformando-se, em certos casos, em eixo para a construção de uma identidade nacional que, caracterizada como não-ocidental, aparece freqüentemente marcada pelo exotismo e/ou pelo atraso. E antes de prosseguir ressaltamos que, mesmo reconhecendo os efeitos "orientalizantes" dessa operação, não se trata aqui apenas de reclamar para o Brasil o estatuto de "ocidental", mas sim de apontar os problemas que a negação de tal estatuto acarreta para a compreensão da sociedade brasileira e também daquelas sociedades às quais se costuma outorgá-lo incondicionalmente.

Os inúmeros trabalhos sobre gênero e homossexualidade realizados no Brasil nas últimas décadas são bastante díspares e não iremos aqui abordá-los em conjunto. Em relação a tal produção, destacaremos os trabalhos do antropólogo Peter Fry, elaborados em grande parte ao longo da década de 1970 e publicados no começo da década seguinte. Analisaremos muito particularmente o artigo "Da hierarquia à igualdade: A construção histórica da homossexualidade no Brasil" ${ }^{2}$, texto crucial para a

1 Ver, a respeito: Carrara, 2004; Moutinho, 2004

2 Essa é a versão publicada de um texto que, conforme conta o autor, teve uma longa história: foi esboçado em 1974 e circulou restritamente no âmbito 
configuração dessa área de estudos e referência quase obrigatória para todos os que nela se aventuram. Interessa-nos, sobretudo, explorar o modo como essa produção foi incorporada por alguns trabalhos subseqüentes. ${ }^{3}$

Acompanhar esse diálogo nos levará ao esforço complementar de situar dois momentos distintos da reflexão sobre as relações entre sexualidade, cultura e política. Em especial, procuraremos reavaliar retrospectivamente o alcance de um conjunto de autores e estudos importantes para a elaboração da reflexão de Fry. Nela, é possível rastrear as bases de alguns dos problemas e conceituações centrais dos atuais estudos sobre sexualidade que, influenciados pelas vertentes pós-estruturalistas e pelos estudos queer, enfatizam a instabilidade/fluidez das identidades sexuais e a imbricação da sexualidade em relações de poder e hierarquias sociais dinâmicas e contextuais.

\section{Homossexualidade entre a tradição $e$ a modernidade}

Em seu artigo sobre a construção histórica da homossexualidade no Brasil, Fry descreve três sistemas taxonômicos que estariam diferencialmente disseminados no país segundo as distintas classes sociais. No primeiro deles, a hierarquia de gênero, articulada a partir da oposição masculinidade/atividade sexual $v$ s. feminilidade/passividade sexual, englobaria de forma sistemática todas as identidades sexuais. A categoria "homem", nesse caso, abarcaria todos os indivíduos do sexo masculino que supostamente mantivessem posição "ativa" em relações sexuais com mulheres ou homens,

acadêmico, recebendo modificações e ampliações posteriores (Fry, 1982:87-115, ver p.112, nota 1 ).

3 Dada a sua importância no campo dos estudos mais recentes sobre a homossexualidade, à sua influência sobre autores estrangeiros e brasileiros e ao seu louvável esforço em entender o contexto local articulado ao contexto global, focalizamos especialmente o livro Abaixo do Equador, do antropólogo Richard Parker (1999 [2002]). 
Sexualidade, cultura e política

indiferentemente. Homens sexualmente "passivos", tratados como "bichas", "viados" etc., seriam percebidos como uma espécie de híbridos, nos quais atributos anatômicos masculinos se misturariam a características de gênero femininas (as famosas almas femininas em corpos masculinos). ${ }^{4} \mathrm{O}$ segundo modelo teria sido formulado, sobretudo, por médicos e psiquiatras e, nele, orientação sexual e gênero se desarticulam progressivamente. ${ }^{5}$ Nos seus termos, os homens que mantivessem relações sexuais com outros homens seriam considerados "homossexuais", não importando mais a posição "ativa" ou "passiva" que assumissem no coito. Aqui, uma certa hierarquia se manteria, mas com base na oposição normalidade/anormalidade-doença, sendo a homossexualidade um desvio doentio ou anômalo em relação à heterossexualidade, instituída em norma. Por fim, historicamente derivado do segundo modelo, o terceiro representaria uma espécie de reação a ele. Mantendo a disjunção entre orientação sexual e gênero e apoiando-se no dualismo hetero/homossexualidade, apenas alteraria o valor dos termos, contestando o estigma de anormalidade ou doença atribuído à homossexualidade. Assim, teríamos um modelo hierárquico (o primeiro) e um modelo igualitário (o último) de construção das

\footnotetext{
4 A caracterização do modelo hierárquico decorreu em grande parte da etnografia realizada por Fry nos terreiros de candomblé da periferia de Belém, em 1974, ao pesquisar, aproveitando a porta aberta por Ruth Landes (2002 [1947]), as relações entre homossexualidade e religiões afro-brasileiras, Cf. Fry, 1982:54-86 - "Homossexualidade masculina e cultos afro-brasileiros". Esse artigo foi primeiramente apresentado na reunião da American Anthropological Association em 1974. Uma versão reduzida foi publicada no primeiro número da revista Religião e Sociedade, em 1977, sob o título "Mediunidade e sexualidade".

5 Em um primeiro momento, o modelo médico-psicológico incorporaria em certa medida os princípios hierarquizantes do gênero, dividindo os homossexuais em "ativos" e "passivos", sendo os últimos os "homossexuais de verdade". Depois, ao longo das décadas de 1940, 1950 e 1960, o modelo caminharia para uma representação mais homogênea dos diferentes tipos, baseada em uma suposta "condição" homossexual.
} 
identidades e categorias sócio-sexuais, mediados pelo modelo médico-psicológico.

A gênese do modelo igualitário é, assim, localizada no pensamento médico da passagem do século, presente tanto na Europa quanto no Brasil. Essa formulação estaria na base dos movimentos gays surgidos na Europa e nos EUA nos anos 1960 que, invertendo o valor atribuído à homossexualidade, fariam, segundo Fry, com que tal taxonomia adquirisse uma "legitimidade avassaladora". Como escreve ele, "De vez, o modelo médico é consagrado pela sua própria criação, a subcultura homossexual" (Fry, 1982:104).

Depois de descrever tal processo de um ponto de vista geral, Fry continua: "E assim se deu no Brasil também" (Id. ib., grifo nosso). A conjunção aditiva "e" é aqui fundamental porque, sem descartar diferenças sociais e culturais, Fry é explícito em sua recusa em ver a difusão de uma identidade homossexual ou gay apenas como mais um exemplo de "dependência cultural":

Quero crer que uma interpretação satisfatória da história que esbocei terá que passar por aquilo que é comum a toda sociedade moderna e capitalista e pelo que é específico de cada uma (Id. ib.:109).

Com suas singularidades, o Brasil faria assim fundamentalmente parte de um processo mais amplo pelo qual passavam diferentes países no chamado mundo ocidental. A emergência do modelo igualitário estaria, segundo o autor, relacionada "com toda uma transformação social das classes médias e altas das grandes metrópoles do país, se não com a própria constituição dessas classes". ${ }^{6}$ Assim, para Fry, tal modelo não estaria apenas mais disseminado nas classes superiores da sociedade brasileira, mas seria um elemento importante na própria construção cultural da identidade de tais classes.

6 Fry (1982:95) acrescenta que "a mesma fração de classe também produz novas identidades para a 'mulher' nesse mesmo período". 
Sexualidade, cultura e política

Fry é cuidadoso em sua proposição de articular sistemas de representação de identidades sexuais a determinadas classes $e$ regiões. Ele observa que as classificações conforme o modelo hierárquico, embora "hegemônicas" nas áreas e populações mencionadas, de certa maneira aparecem "em toda sociedade brasileira, coexistindo e às vezes competindo com outros sistemas" (Id. ib.:91). Mais do que o reconhecimento de várias compreensões da sexualidade masculina, que variariam conforme regiões, classes sociais e situações históricas, o que Fry divisa é a imbricação de sistemas de conhecimento da sexualidade com cosmologias religiosas $e$ ideologias sobre raça, idade $e$ outros marcadores sociais; especialmente a força da linguagem do sexo para expressar concepções de hierarquia $e$ igualdade que remetiam a um contexto mais amplo de disputas políticas.

Embora Fry não o diga claramente, é possível afirmar que o modelo hierárquico não aponta para qualquer traço singular $e$, menos ainda, não-ocidental da sociedade brasileira. Ao contrário, é ele que nos ancora firmemente nessa mesma tradição. Esse modo de organização de práticas e identidades sexuais estava presente nos países europeus desde a Antiguidade ${ }^{7}$, e historiadores puderam identificá-lo até bem recentemente na América do Norte e Europa. ${ }^{8}$ Como diz Dennis Altman, para quem, aliás, o Brasil é definitivamente não-ocidental:

\footnotetext{
7 Ver, por exemplo, Veyne, 1985.

8 São importantes, aqui, os trabalhos de historiadores sociais britânicos, dos quais falaremos adiante. Também George Chauncey (1994:16) ressaltou, em seu estudo histórico, a centralidade da hierarquia de gênero nos sistemas classificatórios das culturas homossexuais masculinas urbanas nos EUA antes da Segunda Guerra Mundial. Segundo ele, fairy e queer eram termos êmicos para designar gradações entre os homens homossexuais mais ostensivamente "afeminados" e mais discretos. Mas tanto fairies como queers almejavam como parceiro ideal um trade, um "homem de verdade", encarnado preferencialmente na figura de um soldado, marinheiro ou trabalhador braçal, que podia se relacionar sexualmente com as fairies ou queers sem ser rotulado com tal, desde que conservasse a aparência masculina e o papel "ativo".
} 
Sérgio Carrara e Júlio Simões

Nos cem anos que precederam o nascimento do movimento gay contemporâneo, a compreensão dominante da homossexualidade era caracterizada pela confusão entre sexualidade e gênero. Em outras palavras, a visão "tradicional" era a de que o homossexual "de verdade" é o homem que se comporta como uma mulher. Algo dessa confusão permanece nas percepções populares (Altman, 1996:82, grifos nossos).

Mesmo sem conseguir apreender a lógica subjacente ao modelo hierárquico, percebida como "confusão", Altman atesta sua presença nos EUA até pelo menos os anos 1950 e, depois disso, sua permanência entre as classes populares. Nesse sentido, identifica, nos EUA, um processo muito semelhante ao que, no mesmo momento, Fry identificava no Brasil. Antes, porém, de seguir adiante, é importante explorar algumas das características daquele "momento", do contexto social, político e intelectual em que o texto de Fry foi produzido.

\section{Uma grande inquietação...}

No Brasil, a virada dos anos 1970 para os anos 1980 não se caracterizou somente pelas discussões que opunham os que consideravam que a questão das "minorias" (negros, índios, mulheres, homossexuais) deveria estar subordinada (ao menos em uma primeira etapa) à questão mais ampla da democratização do país e da revolução social. Como registrou claramente Edward MacRae (1990), em seu trabalho sobre o grupo Somos/SP, o primeiro movimento homossexual brasileiro esteve também profundamente dilacerado quanto a se constituir ou não em torno de uma identidade homossexual. Havia naquele momento uma grande inquietação quanto à possibilidade de essencialização (ou "reificação", para usar uma expressão mais comum à época) da oposição hetero/homossexualidade e da conseqüente instituição de novas formas de rotulação, estigmatização e marginalização. 
Sexualidade, cultura e política

Conforme aponta MacRae, o dilema entre "ser" ou "estar" homossexual foi uma das causas para a fragmentação do grupo Somos/SP (Id. ib.:59). Se inicialmente o grupo "partia do princípio de que a humanidade estaria dividida em heterossexuais $e$ homossexuais (e talvez alguns bissexuais)" (Id. ib.:40), acabaria por incorporar posições mais "relativistas", como as que eram mantidas pelo próprio pesquisador e por alguns militantes. De fato, o trabalho de MacRae é inteiramente transpassado pelo dilaceramento de um pesquisador que sabe que está trabalhando com pressupostos analíticos que podiam enfraquecer os princípios sobre os quais o movimento se organizava naquele momento. A certa altura de seu livro ele corajosamente assume:

Confesso ter sentido perplexidade e desconforto várias vezes em que colegas do mundo acadêmico me incentivaram a discutir o conceito de papel social, pois sentia estar simplesmente emprestando mais um pouco de prestígio (conseguido por mim através da ajuda e confiança dos integrantes do Somos) para uma idéia que só tendia a enfraquecer a sua solidariedade grupal (Id. ib.:41).

O próprio trabalho de Fry não pode deixar de ser lido senão nesse contexto de valorização da ambigüidade, de crítica ao essencialismo e de profunda suspeita quanto ao impacto social dos sistemas dualistas de classificação (ou daquilo que atualmente é chamado de "binarismo"). Como se explicita claramente no final do livro de divulgação $O$ que é homossexualidade, escrito com MacRae em 1983:

Tem muita gente que preferiria não ter que se submeter a estas novas categorias sociais que tendem a empurrá-los para "guetos" estanques. Prefeririam que estas categorias sociais fossem elas mesmas combatidas e acabam entrando em choque não só com a ciência médica mas também com alguns "homossexuais conscientes" que, por razões várias, têm interesse na manutenção das distinções. Afinal, negar a 
inevitabilidade da fronteira que separa os "homossexuais" dos "heterossexuais" colocaria em questão a própria noção de uma identidade homossexual que, para muitas pessoas, representa um modo de dar ordem às suas vidas, cheio de possibilidades de gratificação e muitas vezes "assumido" a duras penas (Fry e MacRae, 1983:120).

A preocupação de autores como Fry, MacRae e, na sua esteira, de Guimarães, Perlongher, Costa e Heilborn', entre outros, não parecia ser apenas com os aprisionamentos identitários, mas com o modo muito particular pelo qual as diferenças de classe podiam agora ser formuladas em termos da adesão mais ou menos completa a um modelo hierárquico ou a um modelo igualitário de compreensão da homossexualidade. Ou seja, o que estava em jogo era a relação "hierárquica" que se estabelecia entre os próprios modelos, convertidos em signos de distinção de classe. Tal "hierarquia" mantinha não apenas intocado o estigma e a reprovação social de que já eram objeto privilegiado homens "afeminados" e travestis, mas o aprofundava, marcando todos eles com a pecha de "atrasados", politicamente incorretos, retrógrados etc.

Ufanismo nacionalista à parte, parece-nos surpreendente como a muito mais recente orientação de se tratar articuladamente diferentes marcadores sociais (de gênero, orientação sexual, raça, classe) já era seguida de modo tão sofisticado no Brasil desde o final dos anos 1970. É também muito interessante notar como inquietações contemporâneas em relação a processos de naturalização das diferenças e a fechamentos identitários,

9 Guimarães, 2004 (originalmente dissertação de mestrado defendida em 1977), apresenta uma etnografia pioneira do que Fry denominou de "modelo igualitário"); Perlongher, 1987; Costa, 1992; Heilborn, 2004 (originalmente tese de doutorado defendida em 1992). Posteriormente, James Green (2000), subscrevendo a visão de um movimento geral do "modelo hierárquico" para o "igualitário" ao longo do século XX, sugeriu haver evidências da existência de identidades que extrapolavam o binário ativo/passivo na cena urbana brasileira desde o início do século. 
Sexualidade, cultura e política

associadas no debate atual ao influente pensamento de autoras pós-estruturalistas, como Judith Butler, já estavam presentes no campo intelectual brasileiro desde o final dos anos 1970. Do mesmo modo, é claramente enunciada e empreendida nesse momento a perspectiva de que o estudo da sexualidade, $e$ especificamente da produção social do dualismo hetero/ homossexualidade (o que hoje se poderia considerar como outro "grande divisor"), mais do que um meio de revelar experiências silenciadas, oprimidas e marginalizadas, era uma chave para o entendimento das convenções culturais e das estruturas de poder mais amplas - ponto esse que hoje se costuma conceder aos revolucionários trabalhos de Eve Sedgwick, entrecruzando teoria literária e sociologia na promoção de uma virada teórica e epistemológica de grande repercussão em várias disciplinas nas humanidades e nas ciências sociais. ${ }^{10}$

Estas observações não pretendem, é claro, ofuscar o brilho do pensamento destas e de outras autoras e autores recentes para o entendimento renovado de questões sociais, políticas e culturais candentes associadas à sexualidade, assim como para a crítica dos nossos próprios regimes de conhecimento. Acreditamos, porém, que uma genealogia menos comprometida a pagar tributos à produção intelectual dos centros metropolitanos deveria seguramente reconhecer a importância do pensamento socioantropológico brasileiro em torno da homossexualidade, seu caráter original e precursor do pensamento crítico que mais tarde viria a ser batizado de teoria queer. ${ }^{11}$ Nosso ponto aqui não é

10 Ver a tradução do texto de Sedgwick e o comentário de Richard Miskolci, neste volume.

11 No Brasil, assim como não chegou a se institucionalizar uma área de estudos gays e lésbicos, também não existe propriamente (pelo menos não ainda) uma área de estudos queer, pelo menos não no mesmo sentido em que ela existe em outros países, sobretudo na academia norte-americana. O significado da palavra queer é extremamente difícil de traduzir em português e, entre nós, para além de alguns círculos de especialistas, a expressão se divulga "empacotada" em seriados americanos e ingleses (como Queer Eye for the Straigth Guy ou Queer as Folk). Significando, segundo o dicionário Oxford, esquisito, estranho, singular 
Sérgio Carrara e Júlio Simões

disputar precedências, mas realçar as afinidades entre certas preocupações analíticas e políticas daquele contexto $e$ do momento atual. Isso requer uma breve consideração do conjunto de referências com as quais dialogavam os antropólogos brasileiros ou aqui aclimatados interessados pela sexualidade $e$ homossexualidade, tendo em vista as contribuições teóricas que marcam atualmente os estudos de sexualidade.

\section{Inventariando antigos diálogos}

No âmbito acadêmico, a discussão sobre homossexualidade nos anos 1970 e 1980 era acompanhada por uma crítica ao próprio conceito de identidade através do diálogo dos antropólogos brasileiros com uma variedade de referências teóricas. Ao leitor contemporâneo, provavelmente saltam à vista as afinidades das idéias e preocupações aqui apresentadas com o pensamento de Michel Foucault. Tal pensamento foi certamente de grande impacto na formatação de uma visão desnaturalizante

e excêntrico, a expressão fazia parte do arcabouço de qualificativos estigmatizantes com os quais, na linguagem comum, delimita(va)-se o lugar socialmente desvalorizado (misto de desonra, perversão e pecado) que a homossexualidade - $e$, nesse caso, sobretudo a homossexualidade masculina devia habitar. Não se pode, entretanto, traduzir queer como sinônimo de "homossexual", uma vez que a expressão se referia particularmente a homens que transgrediam as convenções de gênero ("afeminados", como se diz no Brasil), podendo potencialmente recobrir uma gama ainda mais extensa de práticas e identidades situadas na base das hierarquias sociais de sexo e de gênero. Além da valorização de uma certa marginalidade heróica, de uma postura antiassimilacionista e fortemente crítica das estratégias políticas voltadas para a conquista de direitos e liberdades civis para gays e lésbicas, a teoria queer se caracteriza por um antiessencialismo radical e pela recusa ao fechamento identitário no plano da orientação sexual e do gênero. Daí talvez o caráter estratégico que estados "inter" e/ou "trans" (intersexuais, travestis. transexuais e transgêneros) assumem para essa teoria. "Teoria queer" e "política queer", de todo modo, são expressões que remetem a um leque amplo de conotações, às vezes ambíguas e contraditórias. Ver, a respeito, Epstein, 1996, esp.152-157. Para uma visão geral do contexto político e intelectual de emergência da teoria queer, ver Jagose, 1996 
Sexualidade, cultura e política

da sexualidade, ao sublinhar o papel dos saberes médicos na conformação das modernas identidades sexuais e, sobretudo, por oferecer um poderoso enquadramento conceitual para caracterizar o processo mais amplo de constituição e disseminação de uma modalidade capilar e disciplinar de operação do poder e de exercício do controle social, produtora de novos personagens sociais e novos desafios políticos. O impacto de Foucault se torna mais evidente e intenso a partir da segunda metade dos anos 1970, quando o autor visita o Brasil e obras como Vigiar e punir e História da sexualidade: A vontade de saber ${ }^{12}$ são lidas, traduzidas e passam a freqüentar o debate universitário, coincidindo com a intensificação dos movimentos de oposição à ditadura militar e com a politização crescente das questões ligadas a raça, gênero $e$ sexualidade. Referindo-se ao contexto político e acadêmico brasileiro da época, Fry e MacRae escreveram em 1983:

Até mais ou menos 1975 , os partidos políticos de oposição consideraram que os movimentos feminista, negro $e$ homossexual eram irrelevantes à luta geral, ou seja, a questão das desigualdades entre classes sociais. O que marca os anos mais recentes destas áreas ditas minoritárias é o fato de elas terem chegado a ser reconhecidas também como "políticas", a partir de uma visão da sociedade que enxerga o poder não apenas no Estado, mas também na rua, no escritório, no hospital, dentro de casa e na cama [...]. É justamente nesta época que Michel Foucault compete com os velhos heróis para o primeiro lugar das bibliografias dos cursos de ciências humanas nas universidades (Fry e MacRae, 1983:117). ${ }^{13}$

12 Essas obras, que vieram à luz na França respectivamente em 1975 e 1976, foram ambas publicadas em português no Brasil em 1977. História da sexualidade. A vontade de saber foi publicada em inglês nos EUA em 1978 e no Reino Unido em 1979.

13 Para uma reflexão sobre provincianismos acadêmicos, pode ser interessante comparar as afirmações dos autores com a observação bem mais recente do sociólogo britânico Ken Plummer (2003:518) para quem a importância de 
Se não pode deixar de ser reconhecido, Foucault precisa, porém, ser situado dentre as várias referências que estimulavam a pesquisa e a reflexão sobre sexualidade entre os antropólogos no Brasil nessa época. ${ }^{14}$ Foucault não faz parte da bibliografia do primeiro artigo elaborado por Fry sobre homossexualidade $e$ cultos afro-brasileiros, que apresenta a primeira discussão do sistema de classificação sexual que configura o modelo hierárquico e formula uma interpretação para a significância das categorias sexuais nas definições do que é socialmente considerado "central" ou "normal" e do que é considerado "marginal" ou "desviante". A discussão de Fry aqui evocava em parte as formulações do interacionismo simbólico, mais especificamente na versão da "teoria da rotulação" de Howard Becker (1973) e de suas aplicações etnográficas no estudo da homossexualidade masculina, notadamente o pioneiro $e$ controvertido trabalho de Laud Humphreys, Tearoom trade. Publicado em 1970, esse estudo tratava da organização social do sexo impessoal entre homens em espaços públicos, descrevendo meticulosamente formas de classificação e interação dos praticantes de encontros sexuais nos banheiros públicos

História da sexualidade nos estudos de sexualidade "somente se tornou evidente durante a década de 1980, em grande parte depois da morte de Foucault".

14 Em comunicação pessoal, Mariza Corrêa - participante ativa da cena acadêmica e política que aqui focalizamos - lembrou-nos que, à época em que produziu sua dissertação de mestrado sobre representações jurídicas de papéis sexuais a partir da análise de julgamentos de assassinatos entre casais (escrita em 1975 e mais tarde publicada sob o título Morte em família [1983] e saudada como estudo pioneiro na temática atual da "violência de gênero"), ela havia lido de Foucault apenas as conferências reunidas no livro A verdade e as formas jurídicas, publicado em 1974, originalmente em português. Com efeito, a análise de Corrêa deriva de uma apropriação criativa de diferentes influências teóricas, notadamente as contribuições de antropólogos como Mary Douglas e o primeiro Victor Turner. Foucault se tornaria para ela uma grande influência no momento imediatamente posterior. Ver também, a respeito, Entrevista com Mariza Corrêa, 2003:114 
Sexualidade, cultura e política

(Humphreys, 1970). ${ }^{15}$ Surpreendente produto de seu tempo, a etnografia de Humphreys dissolvia pressupostos convencionais acerca do vínculo estável entre práticas e identidades, ao mostrar a cena do mictório público não como um ponto de encontro de "homossexuais" por excelência, mas como um "caleidoscópio de fluidez sexual"16, e assim antecipando muitas das ênfases atuais nas performances e na desestabilização de categorias sexuais. ${ }^{17}$

15 À época, a notoriedade do livro deveu-se, sobretudo, às questões éticas envolvidas nas técnicas de pesquisa empregadas, que quase levaram à revogação do doutorado do autor. Humphreys localizou quase uma centena de participantes de trocas sexuais nos banheiros públicos e os entrevistou sob a alegação de estar realizando outro tipo de levantamento. Dessa forma, pôde descobrir que a maioria era formada por homens casados, pais de família, religiosos e politicamente conservadores. Para uma reavaliação cuidadosa do contexto e das contribuições substantivas do trabalho de Humphreys, ver: Irvine, 2003:esp.441-446.

16 Outra etnografia importante enfocando aspectos da vida homossexual de modo a acentuar a separação entre práticas e identidades foi a de Albert Reiss Jr. (1967), originalmente escrita em 1961, sobre as transações sociais e sexuais entre garotos de programa (peers), que não se consideravam "homossexuais", e seus clientes (queers), mostrando as convenções que ordenavam as relações entre eles. Os peers deveriam sempre manter o papel sexual masculino (de "introdutor", como classificaria Humphreys mais tarde) e tanto eles como os clientes mais velhos deviam motivar-se sexualmente apenas por dinheiro, jamais por afeto. A etnografia de Humphreys ia comparativamente mais fundo na dissolução dos pressupostos a respeito de identidades sexuais fixas, interpretando os papéis sexuais como decorrência das interações naquele espaço. Conforme observa Irvine (2003:444), enquanto "Queers and peers" "retratava um sistema sexual organizado pela manutenção rígida dos papéis sexuais", Tearoom trade era "um caleidoscópio de fluidez sexual, em que os homens passavam do papel $\mathrm{de}$ 'introdutor' para o de 'receptor' com grande diligência, às vezes durante um único encontro".

17 A avaliação das contribuições teóricas, empíricas e políticas das pesquisas sociológicas sobre homossexualidade na perspectiva do interacionismo simbólico, das teorias da rotulação e do conceito de estigma ainda é matéria de controvérsia. Para Steven Seidman (1996), embora "grande parte dessa sociologia procurasse retratar os homossexuais como vítimas de uma discriminação injusta", ela teria contribuído ao mesmo tempo "para a percepção pública do homossexual como um tipo estranho e exótico, em contraste com o heterossexual normal e respeitável". Em contraste, outros comentadores 
O próprio trabalho de Humphreys era desaguadouro de uma série de tendências na sociologia norte-americana dos anos 1960 que incluíam, além da reconceituação do "desvio" feita por Becker, a abordagem dramatúrgica de Goffman, a etnometodologia de Garfinkel e a abordagem pragmática, desnaturalizante e antipsiquiátrica da sexualidade desenvolvida por John Gagnon e William Simon, que concebiam o "sexual" como realizações sociais ordinárias, fruto de um complexo de negociações e definições sociais que se davam em diferentes nichos da vida cotidiana. Os trabalhos desses autores ficaram marcados pelo esforço de compreender os modos processuais $e$ contingentes pelos quais as pessoas assimilavam estilos de vida $e$ os punham em prática, assim produzindo e modificando a própria percepção e apresentação de si. Esse estilo de abordagem se expressa no uso da metáfora da "carreira", que desempenha papel importante na reflexão de vários deles. ${ }^{18}$

apresentam esses trabalhos como precursores importantes (e injustamente desvalorizados) dos atuais estudos sobre sexualidade. Ver, por exemplo, a alentada revisão de Janice Irvine (2003); ver também: Epstein, 1996 e Rubin, 2002. Todos os artigos publicados na edição especial Social Theory and Sexuality Research, 1910-1978 da revista Qualitative Sociology (26), 4, 2003, são extremamente relevantes para esta discussão.

18 Ver as referências de John Gagnon (2006:403-424) a respeito da noção da "carreira" como herança duradoura da Escola de Chicago na entrevista a Gunther Schmidt - "Revisitando a conduta sexual". Para ilustrar esse ponto, podemos recordar a noção de "carreira desviante" usada por Becker (1973) em seu pioneiro estudo de usuários de maconha, assim como da noção de "carreira moral" de Goffman (1975), de como as pessoas ameaçadas de sofrer descrédito constroem e/ou aprendem a participar de valores e afiliações sociais alternativas. Lembremos ainda da noção de "passing" cunhada por Garfinkel (1967)para dar conta das estratégias de produção e manipulação da identidade de gênero postas em práticas no famoso caso de Agnes, a jovem transexual que se fez passar por intersexual e assim obteve autorização para se submeter à cirurgia de transgenitalização, a primeira desse tipo realizada nos EUA em 1959. O modelo da "carreira" foi aplicado por Plummer (1975) e outros para pensar o desenvolvimento da identidade homossexual em face do estigma social. Para um comentário a respeito, ver Simões, 2004. 
Sexualidade, cultura e política

Embora esses autores não compartilhassem inteiramente as mesmas formações e filiações teóricas, tinham em comum a visão de que qualquer comportamento humano, inclusive sexual, era sempre submetido à avaliação moral, sendo portanto uma realização social. Isso se afastava tanto da abordagem psicanalítica como da visão de Alfred Kinsey, que, mesmo percebendo a gênese social de categorias como homo e heterossexualidade, divisava o cerne da sexualidade em comportamentos corporais individuais objetivamente mensuráveis, ligados à excitação $e$ ao orgasmo. Aqueles sociólogos, em contraste, não apenas distinguiam práticas e identidades, mas procuravam compreender os modos pelos quais a sexualidade era regulada e reinventada na dinâmica da interação social por meio de operação de categorias estruturantes - o que, no jargão mais afinado com a sociologia clássica francesa, poderíamos chamar de "representações".

Em seu artigo sobre a construção histórica da homossexualidade masculina no Brasil, Fry propõe uma abordagem bem semelhante, porém com mais ênfase nas "representações" do que nas sutilezas do comportamento cotidiano. Para tanto, ele se voltava para a interrogação pioneiramente formulada por Mary McIntosh (1968) sobre as condições sociais que tornaram possível pensar a "homossexualidade" como uma condição humana singular e o "homossexual" como uma categoria capaz de expressar um atributo identitário fundamental e uma conduta adequada correspondente. McIntosh reuniu evidências sociológicas $e$ históricas disponíveis em 1968 para sugerir que, embora desejos e comportamentos homossexuais pudessem existir em diferentes épocas e sociedades, somente em algumas se produzia uma identidade homossexual específica, conforme preocupações com as definições e os limites do que é aceitável em termos de conduta sexual. É o que teria ocorrido na Inglaterra, desde o final do século XVII. O passo seguinte de McIntosh foi reexaminar os dados de Kinsey relativos à escala de gradação entre comportamentos homossexuais $e$ heterossexuais, para sugerir que a maior 
concentração de homens no grau de comportamento homossexual exclusivo se devia ao efeito coercitivo da existência histórica de um papel homossexual mais desenvolvido para os homens nas sociedades anglo-americanas. Como comenta Fry:

McIntosh argumenta que a existência de um rótulo fortemente desenvolvido constrange o comportamento no sentido de fazê-lo conformar-se às expectativas sociais $e$ sexuais geradas por esse rótulo. Assim, de certa forma, as taxinomias são profecias que se cumprem. Postula-se, por exemplo, a existência de um tipo natural, o homossexual com sua essência e especificidade, e ele logo passa a existir (Fry, 1982:89).

A reflexão de Fry passa daí a incorporar o trabalho de historiadores sociais britânicos como Jeffrey Weeks e John Marshall que, na esteira dos insights de McIntosh, ressaltam o papel dos discursos científicos na produção da "condição homossexual", reunindo evidências da preocupação social com o controle da libido masculina, que as teorias médicas da época acreditavam estar tanto na raiz da homossexualidade quanto nas relações sexuais fora do casamento em geral, incluindo a prostituição, representando uma ameaça à integridade da família $e$ à saúde física e moral da própria nação. ${ }^{19}$ Esses autores foram uma inspiração importante para a compreensão das especificidades do processo semelhante em curso no Brasil do início da República, envolvendo as mesmas conexões entre homossexualidade, loucura e crime. Eles ofereciam mais

19 Cf. Weeks, 1977; Marshall, 1981. Sobre a influência de McIntosh nesses trabalhos, ver: Weeks, 1998. O trabalho desses historiadores costuma ser ofuscado pelas pesquisas e reflexões de Foucault, que se desenvolviam paralelamente, deixando de ser reconhecido como igualmente importante para a formulação do que ficou conhecido como teoria da construção social da sexualidade. Isso tem sido acusado em várias revisões recentes do campo da sexualidade nas ciências humanas. Ver, por exemplo, Vance, 1995; Epstein, 1996; Rubin, 2002; Irvine, 2003. 
Sexualidade, cultura e política

evidências de que sistemas classificatórios da sexualidade masculina equivalentes ao "modelo hierárquico", segundo idéias rígidas de "masculinidade" e "feminilidade" associadas à dicotomia ativo/passivo, vigoravam no mundo ocidental industrializado ainda no início do século $\mathrm{XX} .^{20}$

É preciso reservar um lugar especial neste breve inventário de antigos diálogos para a antropóloga Mary Douglas, notadamente sua preocupação com o papel das categorias relacionadas a ambigüidades $e$ anomalias na organização da experiência social, pelo desafio que propõem ao controle e à coerência dos princípios classificatórios. ${ }^{21} \mathrm{Na}$ reflexão de Douglas, as sociedades expressam uma estrutura formal com idéias e áreas bem definidas de separação entre ordem e desordem, bem como de punição das transgressões. As ambigüidades e anomalias situadas nos interstícios e fronteiras dos sistemas classificatórios trazem a desordem que destrói os padrões, mas também fornecem a matéria-prima da padronização. A própria desordem tem, portanto, um estatuto ambíguo, na medida em que representa não somente a ameaça de destruição, mas também o potencial criativo: simbolizando poder e perigo, não pode ser simplesmente expurgada sem conduzir à derrocada todo senso de ordem social e simbólica (Douglas, 1976:117). Essas idéias haviam sido exploradas por Fry para interpretar a correlação entre homossexualidade e cultos afro-brasileiros, ambos sendo classificados como "marginais", perigosos e, portanto, dotados de poderes especiais. Na discussão sobre a construção histórica da homossexualidade masculina, elas reaparecem para corroborar a concepção segundo a qual os sistemas de classificação dualistas seja a oposição hetero/homossexual, ou homem/bicha - são meios

20 Além de reconhecer essa influência na orientação teórica de seu ensaio, Fry (1982:112-113) informa que a conceituação das identidades sexuais afetivas considerando quatro componentes básicos (sexo biológico, papel de gênero, comportamento sexual e orientação sexual), usada na elaboração dos modelos classificatórios, era tomada do trabalho de John Marshall.

21 Cf. Douglas, 1976 [1966], esp. Introdução e cap. 6. 
para uma "supersistematização expressiva" voltada para controlar uma experiência "inerentemente desordenada" (Id. ib.:15). e, assim, reduzir a ambigüidade $e$ a anomalia, "fontes de poder $e$ poesia que pela sua própria natureza habitam os espaços dos limites do "normal' e do cotidiano" (Fry, 1982:109). ${ }^{22}$

É interessante notar como essas idéias de Douglas reaparecem nas teorias de Judith Butler sobre corporalidade $e$ performatividade de gênero, de grande repercussão nos estudos atuais de sexualidade dentro de uma perspectiva queer. Para Butler, as categorias de gênero operam como tabus sociais que exageram a diferença sexual, visando naturalizá-la e assegurar a heterossexualidade por meio da instituição ritual e reiterada das fronteiras do corpo (Butler, 2003, 1993). A reflexão de Butler num primeiro momento se apóia fortemente nas observações de Douglas, de que as fronteiras do corpo (orifícios e superfícies), simbolizando os limites do social, são regiões perigosas de permeabilidade que requerem policiamento $e$ regulação constantes, daí decorrendo observações sobre a homossexualidade (sobretudo masculina) como lugar de perigo $e$ poluição. Butler reconhece em Douglas a sugestão de que a própria noção da integridade do corpo como algo distinto $e$ naturalizado 23 é produto dessas regulações. "Além disso", acrescenta Butler:
os ritos de passagem que governam os vários orifícios corporais pressupõem uma construção heterossexual da troca, das posições e das possibilidades eróticas marcadas pelo gênero. A desregulação dessas trocas rompe, conseqüentemente, as próprias fronteiras que determinam o que deve ser um corpo. Aliás, a investigação crítica que

22 Ele prossegue mencionando o trabalho de Walnice Galvão sobre o romance Grande Sertão: Veredas e a etnografia de R. Lobert sobre o grupo Dzi Croquettes como exemplos de estudos que tomam a ambigüidade como fonte de criação artística. Cf. Galvão, 1972; Lobert, 1979.

23 Cf. Douglas, 1976:esp. caps.7, 8 e 9. 
Sexualidade, cultura e política

levanta as práticas reguladoras no âmbito das quais os contornos corporais são construídos constitui precisamente a genealogia do "corpo" em sua singularidade, capaz de radicalizar a teoria de Foucault (Butler, 2003:190).

Não é possível irmos mais longe nesta digressão. ${ }^{24}$ Acreditamos que o exposto é suficiente para evidenciar a riqueza e a fertilidade dos diálogos e discussões travadas no ambiente acadêmico do Brasil nas décadas de 1970 e 1980 então engajado no estudo da homossexualidade e nos esforços de desvendar a articulação da sexualidade a outras hierarquias sociais. A avaliação retrospectiva não apenas mostra o paralelo dessas preocupações com parte importante da produção intelectual nos centros metropolitanos - inclusive no prenúncio de vertentes contemporâneas do pensamento feminista e dos chamados estudos queer - como também sugere até algumas vantagens para a produção "nativa". Com efeito, se mesmo os mais compreensivos resenhadores das tradições socioantropológicas anglo-americanas de estudo da sexualidade nos anos 1960 e 1970 criticam nelas a pouca atenção conferida às estruturas institucionais e a ausência de uma análise abrangente sobre poder e desigualdade $e^{25}$, não se pode dizer que tais temas e questões estivessem fora do horizonte da reflexão que vimos focalizando.

24 Uma consideração mais abrangente do ambiente dos anos 1980, que excede os limites deste texto, deveria arrolar autores como Gilles Deleuze e Felix Guattari (1972), importantes para o debate político daquele momento e influentes no trabalho de Perlongher (1987), assim como Louis Dumont (1983), relevante para o estudo de Heilborn (2004), ou mesmo Richard Rorty (1979), referência para a reflexão um pouco posterior de J. F. Costa (1992).

25 Cf. Irvine, 2003:449. Note-se que mesmo cientistas sociais mais entusiastas da teoria queer criticam-na pelo enfoque excessivamente "textual" e pelo desinteresse de teorizar e pesquisar a relação entre o institucional e o discursivo. Ver, por exemplo, Gamson, 2006. 
Sérgio Carrara e Júlio Simões

\section{Identidade homossexual, identidade nacional}

A reflexão desenvolvida nos anos 1970 e divulgada no início dos anos 1980 será revisitada por muitos antropólogos e antropólogas nos anos 1990. Nesse contexto, inaugurado pelo advento da AIDS, multiplicam-se os estudos sobre a homossexualidade masculina no Brasil, conduzidos tanto por brasileiros quanto por estrangeiros. Nessa produção, destaca-se a reflexão de Richard Parker que, em seu livro Abaixo do Equador, busca abordar sistematicamente a interação da "subcultura" homossexual que se consolida pós-AIDS no Brasil com a trajetória de comunidades semelhantes nos países "centrais". ${ }^{26}$

Em muitos aspectos Parker acompanha a argumentação de Fry, contribuindo de modo significativo para a manutenção, ao longo dos anos 1990, de uma perspectiva anti-essencialista, atenta às possíveis dissonâncias entre práticas sexuais, identidades $e$ categorias classificatórias. Parker faz, entretanto, um deslocamento significativo em relação à posição ocupada pelo modelo hierárquico. O que era antes atribuído por Fry às classes populares passa a ser a tradição, ou seja, signo distintivo e singular da cultura e da sociedade brasileiras em relação a um mundo que Parker designa, sem maiores qualificações, como "angloeuropeu". O modelo baseado na hierarquia de gênero e na

26 Cf. Parker, 2002:23. A abordagem do livro é definida na esteira de uma breve discussão crítica da polaridade essencialismo/construcionismo: "Tanto na pesquisa da identidade essencial como na afirmação da diferença radical, somos empurrados para extremos superficiais, que basicamente não conseguem apreender a realidade quase sempre confusa da vida no mundo moderno e pósmoderno contemporâneo, globalizado e globalizante - um mundo [...] em que um conjunto de relações complexas de fato existe e é marcado por processos de mudança social, cultural, econômica e política que essencialmente ligam o Ocidente ao Resto, como parte de um sistema interativo". Desenhando um amplo panorama da emergência da comunidade gay brasileira, a proposta do autor é explicitamente ultrapassar abordagens simplistas que oporiam "the West to the Rest", daí ser tão interessante analisar como ele o faz à luz das idéias até aqui discutidas. 
Sexualidade, cultura e política

oposição atividade/passividade sexual estaria, para o autor, enraizado no sistema cultural e social formado "em torno de um modo concreto de produção, a economia rural de plantation", que teria dominado a vida brasileira por quase quatro séculos, desaparecendo apenas parcialmente em um período mais recente da história do país (Parker, 2003:54). ${ }^{27}$ Embora mais antiga, essa gramática cultural continuaria a influenciar fortemente a experiência sexual no Brasil, fazendo recair o estigma geralmente sobre os sexualmente passivos e socialmente femininos.

Para Parker, a noção de homossexualidade como uma categoria sexual distinta seria relativamente nova $e$ as idéias relacionadas à identidade gay teriam emergido nas últimas décadas do século XX, no confronto da tradição brasileira com um "conjunto mais amplo de símbolos culturais e significados sexuais em um sistema mundial cada vez mais globalizado" (Id. ib.:53). Como se vê, processos que antes apareciam como desenvolvimentos paralelos e nos quais se poderiam encontrar algumas características comuns e outras singulares, surgem agora sob o modelo da "influência", da "importação" e "exportação" cultural. Isso fica explícito quando o autor diz ser sua intenção contribuir para preencher uma lacuna no campo dos estudos sobre a homossexualidade, pois, embora a invenção das categorias relacionadas à nova ênfase na orientação sexual no discurso médico e científico ocidental já tenha sido descrita em detalhe por inúmeros autores, "a exportação e importação dessas categorias fora do mundo anglo-europeu quase não receberam atenção nenhuma". (Id. ib.:66, grifos nossos)

Parker também relaciona o aparecimento de uma identidade sexual baseada na orientação sexual à urbanização, à emergência das classes médias e sua profissionalização. Mas não haveria aqui qualquer conexão interna entre a constituição das classes médias ou da burguesia e o sistema homo/

27 Em apoio dessa afirmação, Parker cita o clássico de Gilberto Freyre, Sobrados e mucambos. 
Sérgio Carrara e Júlio Simões

heterossexualidade articulado inicialmente pelo pensamento médico. ${ }^{28}$ Para Parker, na passagem do século XIX para o século $\mathrm{XX}$, os emergentes profissionais especializados brasileiros (acadêmicos, advogados e médicos) estariam sendo educados nos grandes centros europeus e, por meio deles, teria havido "a importação e incorporação crescentes na realidade brasileira" de todo um novo conjunto de disciplinas científicas, racionalidades e novos modos de conceituação da experiência sexual:

Em especial, um novo modelo médico-científico de classificação sexual - introduzido na cultura brasileira, pelo menos inicialmente, por meio dos textos de médicos, psiquiatras e psicanalistas, e traduzidos gradualmente para o discurso mais amplo da cultura popular - parece ter marcado uma mudança fundamental na atenção cultural, passando da distinção entre os papéis ativo $e$ passivo, como suporte da hierarquia de gênero, para a importância, de acordo com as linhas anglo-européias, do desejo sexual e, em particular, da escolha do objeto sexual como básica para a própria definição do sujeito sexual (Id. ib.:65-66, grifos nossos).

No Brasil, até os anos 1960 e 1970, tais categorias teriam ficado restritas a uma elite altamente educada, em contato com a cultura "anglo-européia" e influenciada por ela. Depois disso, a confluência de certos processos econômicos, como a emergência de um pink market ${ }^{29}$ no país, e sócio-políticos, como a

28 Parker observa que a burguesia brasileira ascendente, ligada ao aparecimento de um novo mundo de profissionais especializados, poderia ser talvez considerada "decadente, já que pode ser compreendida, em muitos aspectos, como uma reedição da classe de plantation" (Id. ib.:65), citando novamente o clássico de Freyre em seu apoio.

29 Na edição brasileira, a expressão é traduzida como "mercado gay" (cf. Parker, 2002:82 e 128-129). Conforme Parker, "esse circuito comercial e a economia especializada em rápido crescimento que surgiu a partir dele tornaramse fundamentais para a construção de um mundo gay mais amplo no Brasil. Ainda mais claramente do que as formas culturais de pegação e prostituição (que 
Sexualidade, cultura e política

atuação dos grupos anti-AIDS ${ }^{30}$ e, embora menos crucial, também de grupos compondo um "movimento gay" - "novamente", afirma Parker, "baseado em aspectos importantes nos modelos anglo-europeus" (Id. ib.:71) - levaria, a partir dos anos 1990, à constituição de uma exuberante comunidade gay nacional.

Segundo Parker, além de um ritmo mais lento de emergência (explicado pela teoria do desenvolvimento dependente que teria "atrasado" a estruturação do pink market nacional), o que marca a comunidade gay brasileira seria, sobretudo, a permanência de distinções hierárquicas "tradicionais" (ativo/passivo), explicada pelo fato de o modelo econômico vigente manter e aprofundar as desigualdades sociais, reforçando, portanto, segundo o autor, o próprio caráter hierárquico da sociedade brasileira. Tal permanência do "velho", articulada às novas categorias "importadas", determinaria uma profusão de categorias e de tipos sexuais (Id. ib.:82) que, com a chamada globalização, estariam agora sendo "exportados" (sobretudo nas figuras de michês e travestis) para os países europeus e os EUA. É principalmente aqui, na glamorosa figura das travestis, que o autor

são, é claro, em muitos sentidos transnacionais), o circuito comercial gay simultaneamente liga a realidade brasileira a um conjunto mais abrangente de trocas internacionais econômicas e simbólicas, embora adapte esse sistema internacional às particularidades do contexto e dos costumes locais" (Id. ib.:130131).

30 Como escreve Parker (2002:136), "no Brasil (como em muitos outros países em desenvolvimento), a presença da Aids antecedeu o grande crescimento de um movimento gay". "A incorporação de modelos de prevenção à Aids e o financiamento (por parte de instituições como o USAID, a Organização Mundial da Saúde ou o Banco Mundial) de projetos destinados a populações específicas, como 'homens que fazem sexo com homens', foram algumas das formas mais visíveis em que as estruturas conceituais e os significados sexuais - desenvolvidos em outros contextos sociais, quase sempre bem diferentes - se incorporaram à vida brasileira, configurando o mundo gay em transformação em várias formas bastante específicas". (Id. ib.:139) 
Sérgio Carrara e Júlio Simões

localiza o impacto das elaborações culturais brasileiras sobre a cena gay internacional. ${ }^{31}$

\section{Conclusões}

O trabalho de Richard Parker é sem dúvida instigante, mas, do nosso ponto de vista, revela ainda a manutenção de um esquema analítico problemático. Em primeiro lugar, a transformação do popular em nacional é tão temerária quanto o enraizamento da "tradição brasileira" em um modo de produção particular, a plantation. Como a oposição ativo/passivo $e$ as categorias sexuais que organizava estavam presentes em lugares em que não havia plantation, como os países europeus, a maior parte dos EUA e vários outros da própria América Latina, a afirmação se reduz a uma espécie de fantasia economicista.

Em segundo lugar, o recurso a uma tradição peculiar, em cujos termos as novidades importadas são incorporadas $e$ transformadas, faz com que a cultura brasileira e latino-americana apareçam como essencialmente diferentes das culturas do Norte (ou, ao menos, parte-se de uma diferença essencial). ${ }^{32} \mathrm{~A}$ sociedade brasileira "se defronta" $e$ "interage" com o Ocidente como se não tivesse sido parte dele desde sempre. O esforço de Parker em ultrapassar uma abordagem simplista da relação "norte"/"sul" ou "centro"/"periferia" deve ser reconhecido, mas, em seu modelo de análise, as culturas periféricas somente seriam

31 Conforme Parker (2002:275), "Esse movimento [de travestis] entre o Brasil e a Europa meridional tornou-se o fluxo populacional principal... Ele liga o mundo gay brasileiro a um universo internacional mais amplo, e tem sido uma parte importante da globalização crescente de homossexualidades brasileiras nos últimos anos".

32 Ainda para ilustrar esse ponto, podemos observar que, para Parker, termos como "bicha", "viado", "boiola" etc. têm "um status ontológico diferente dos seus equivalentes em língua inglesa" porque "são produzidos em um sistema distinto de sexo/gênero, e a circulação do estigma associado a essas figuras (no Brasil ou nas outras sociedades latinas) é qualitativamente diferente do estigma e da opressão que marcam o espaço da 'queer' ou 'faggot' em inglês" (Id. ib.:60). 
Sexualidade, cultura e política

"ativas" dentro dos limites impostos por uma "passividade" englobante ou estrutural. O movimento inicial que acontece no "centro" independe delas. Elas o incorporam, processam $e$, dadas certas circunstâncias especialíssimas, conseguem exportá-lo reelaborado. O movimento tem sua origem sempre em seu "exterior".

Do nosso ponto de vista, a atuação das "periferias" é bastante mais complexa. "Ativas" ou "passivas" são sempre coprodutoras do que acontece nas metrópoles, mesmo que seu papel nesse sentido quase nunca seja reconhecido. São coprodutoras não apenas por aquilo que "exportam" (e não "exportam" apenas categorias sexuais, mas também elaborações teóricas), mas pelo que através delas, ou em seu nome, é mantido no "centro". Basta imaginar como os países "centrais" seriam diferentes sem a rede de pesquisadores, financiadores, agentes governamentais e não-governamentais etc. que dentro deles se constitui e se justifica pela existência desse "Rest", que precisa ser estudado, compreendido e socorrido.

Além disso, ao não destacar a descontinuidade e o conflito no seio do movimento homossexual brasileiro, Parker acaba não explorando o impasse que, em um primeiro momento, girou em torno da identidade homossexual e a recusa em tratá-la como identidade quase-étnica. ${ }^{33}$ Obscurece-se assim a importância de intelectuais, como Fry, MacRae, Guimarães e Perlongher, e de vários ativistas que souberam evitar que a legitimidade das novas categorias se tornasse realmente avassaladora. Sua atuação não nos parece menos importante do que a dos determinantes econômicos para entender porque travestis e michês não foram completamente demonizados pelo chamado "movimento gay" nascente. Vale a pena nos determos um pouco mais neste ponto.

Em que pese o rastro de morte e violência que acompanhou seu avanço, a Aids mudou dramaticamente as

33 Sobre a identidade quase-étnica associada à homossexualidade, ver: Murray, 1979; Epstein, 1987. 
normas da discussão pública sobre a sexualidade ao deixar também como legado uma ampliação sem precedentes da visibilidade $e$ do reconhecimento da presença socialmente disseminada dos desejos e das práticas homossexuais. A mobilização de prevenção e combate à Aids no Brasil organizouse concomitantemente sobre o pano de fundo da recusa às identidades sexuais fechadas, em que organizações como a Associação Brasileira Interdisciplinar de Aids - ABIA (da qual Parker foi diretor-executivo) tiveram um papel fundamental na crítica à idéia de grupos de risco e na promoção da aliança entre ativistas homossexuais e hemofílicos de modo a construir a Aids como um problema de todos. Nesse processo, a experiência da primeira onda de militância homossexual no final dos 1970, que convivia com a crítica de acadêmicos e ativistas que problematizavam a questão da identidade homossexual, foi tão importante quanto o estabelecimento de parcerias e alianças com agências governamentais e organizações internacionais.

Deve-se ressaltar ainda que o movimento homossexual que emerge nos anos 1990 apresenta uma configuração polimorfa, abrangendo, além de grupos de orientação mais comunitarista, setores de partidos políticos, ONGs, associações estudantis e até grupos religiosos. ${ }^{34} \mathrm{Se}$, nesse contexto, as conexões intensificadas do movimento com as agências estatais e o mercado segmentado contribuem para reforçar a adesão a um sistema classificatório baseado na distinção de orientação sexual, vemos também que a multiplicação de categorias destinadas a nomear o sujeito político do movimento, manifesta na atual sigla GLBT ("gays, lésbicas, bissexuais, travestis e transexuais"), é proposta em diálogo crítico com outras, como GLS ("gays, lésbicas e simpatizantes"), do mercado segmentado, que reelaborava a ambigüidade classificatória para ampliar o potencial de inclusão; ou $\mathrm{HSH}$ ("homens que fazem sexo com homens"), das políticas de saúde,

34 Para uma análise do movimento homossexual no Brasil nos anos 1990, ver Facchini, 2005. 
Sexualidade, cultura e política

que, talvez equivocadamente, buscavam contornar o problema da falta de coincidência entre comportamentos e identidades sexuais. ${ }^{35}$ Importa salientar, de todo modo, que a tensão entre as aspirações inclusivas e pluralistas, de um lado, e a adesão compulsória à lista de identidades reconhecidas como alvo da ação do movimento, de outro, não tem levado somente a conflitos amargos e autodestrutivos, mas também a iniciativas bemsucedidas como as "Paradas do Orgulho GLBT", expressões de um espaço inclusivo de atuação política por meio de uma peculiar celebração das possibilidades de convivência com a diversidade sexual. ${ }^{36}$

Finalmente, parece-nos ainda que os problemas apontados aqui em abordagens como a de Parker estão ligados à dificuldade

35 HSH fez parte de uma estratégia epidemiológica que se supunha contemplar a especificidade do contingente de homens que se relacionavam sexualmente com pessoas do mesmo sexo e não se reconheciam como "homossexuais", "gays", "entendidos" etc. A categoria HSH também esteve ligada à promoção do conceito de "homoerotismo" como termo preferível à "homossexualidade", tendo em vista, conforme argumentava Jurandir Freire Costa (1992:11), romper com "costumes morais prisioneiros do sistema de nominação preconceituoso que qualifica certos sujeitos como moralmente inferiores pelo fato de apresentarem inclinações eróticas por outros do mesmo sexo biológico". Costa advertia que a carga de preconceito contida em termos como "homossexualidade", "homossexualismo" e "homossexual" era de tal ordem que seu uso acarretava conseqüências éticas funestas independentemente da intenção moral de quem os usasse. De outra parte, HSH teve sua eficácia questionada por ativistas como Luiz Mott (2000:14), para quem o termo "não sensibiliza nem os 'homens' que transam com gays e travestis, que não consideram seus parceiros 'homens', mas 'bichas', deixando de atingir igualmente boa parcela das próprias 'bichas $e$ travestis', que não se identificam como "homens". Um problema com a categoria HSH é dissolver a questão da não-correspondência entre desejos, práticas e identidades numa formulação que recria a categoria universal "homem" com base na suposta estabilidade fundante do sexo biológico, ao mesmo tempo em que permite evocar as bem conhecidas representações da sexualidade masculina como inerentemente desregrada e perturbadora.

36 Para uma reflexão sobre o caráter situacional e político das ênfases na estabilização e na multiplicidade das identidades coletivas, ver Gamson, 1995. Para uma análise da Parada do Orgulho GLBT de São Paulo, ver França, 2006. 
que demonstram em acessar a dimensão propriamente cultural da construção das identidades sexuais no Brasil e sua transformação ao longo do período analisado. No final do artigo "Da hierarquia à igualdade", Fry se perguntava em tom quase melancólico se enfim estaríamos fadados a permanecer em sociedades dualistas (homem/bicha, hetero/homo etc.). Porém, o que provavelmente não estava muito claro para ele naquele momento era que a recusa do dualismo não era apenas affair universitário, encontrava ressonância na própria sociedade brasileira, pois o que talvez venha realmente marcando a singularidade brasileira seja menos a ênfase na oposição ativo/passivo ou em outros binarismos hierárquicos $e$ mais a recusa em operar com dualismos $e$ identidades essencializadas, incomensuráveis e intransitivas. ${ }^{37} \mathrm{E}$, ressalte-se, mesmo essa recusa não pode ser compreendida como parte de nossa tradição não-ocidental, mas sim como o modo particular pelo qual elaboramos tal tradição.

\section{Referências bibliográficas}

AltMAN, Dennis. Rupture or continuity? The internationalization of gay identities. Social Text (14), 3, 1996.

BECKER, Howard. Outsiders. Studies in the sociology of deviance. Nova York, The Free Press, 1973.

Butler, Judith. Problemas de gênero. Feminismo e subversão da identidade. Rio de Janeiro, Civilização Brasileira, 2003 [1990]. Bodies that matter. Nova York, Routledge, 1993.

CARRARA, Sérgio. Estratégias anticoloniais: sífilis, raça e identidade nacional no Brasil de entreguerras. In: HOCHMAN, Gilberto; ARMUS, Diego. (orgs.) Controlar, curar. Ensaios históricos sobre saúde e doença na América Latina e Caribe. Rio de Janeiro, Fiocruz, 2004, pp.427-453.

37 Para uma análise do modo particular como a recusa em assumir uma identidade sexual estanque se articula a valores mais amplos mantidos pelas classes médias urbanas brasileiras, ver Heilborn, 1996. 
Sexualidade, cultura e política

CHAUnCEY, George. Gay New York. Gender, urban culture and the making of the gay male world, 1890-1940. Nova York, BasicBooks, 1994.

CORREAA, Mariza. Entrevista. Cadernos de Campo - Revista dos Alunos de Pós-Graduação em Antropologia Social da USP (11), 2003. . Morte em família. Rio de Janeiro, Graal, 1983.

CostA, Jurandir Freire. A inocência e o vício. Estudos sobre o homoerotismo. Rio de Janeiro, Relume Dumará, 1992.

Deleuze, Gilles e GuATtari, Félix. L'anti-Oedipe. Paris, Minuit, 1972.

Douglas, Mary. Pureza e perigo. São Paulo, Perspectiva, 1976 [1966].

DUMONT, LOUIS. Essais sur l'individualisme: Une perspective anthropologique sur l'idéologie moderne. Paris, Gallimard, 1983.

EPSTEIN, Steven. A queer encounter: sociology and the study of sexuality. In: SEIDMAN, Steven. (org.) Queer theory/ Sociology. Cambridge, MA, Blackwell, 1996.

. Gay politics, ethnic identity: the limits of social constructionism. Socialist Review (93/94), 1987, pp.9-54.

FACCHINI, Regina. Sopa de letrinhas? Movimento homossexual e produção de identidades coletivas nos anos 90. Rio de Janeiro, Garamond, 2005.

FRANÇA, Isadora Lins. Cercas e pontes. O movimento GLBT e o mercado GLS na cidade de São Paulo. Dissertação de mestrado, Antropologia Social, USP, 2006.

FRY, Peter. Para inglês ver. Identidade e política na cultura brasileira. Rio de Janeiro, Zahar, 1982. Brasiliense, 1983.

e MACRAE, Edward. O que é homossexualidade. São Paulo, . Mediunidade e sexualidade. Religião e Sociedade, $\mathrm{n}^{\circ} 1$, 1977.

FouCAULT, Michel. A verdade e as formas jurídicas. Rio de Janeiro, Cadernos da PUC, 1974.

. Vigiar e Punir. Petrópolis, Vozes, 1977.

. História da Sexualidade - A vontade de saber. Rio de Janeiro, Graal, 1977. 
Sérgio Carrara e Júlio Simões

GAGNON, John. Uma interpretação do desejo. Rio de Janeiro, Garamond, 2006 [1998].

GALVÃo, Walnice N. As formas do falso. São Paulo, Perspectiva, 1972.

GAMSON, Joshua. As sexualidades, a teoria queer e a pesquisa qualitativa. In: DENZIN, Norman et alii. O planejamento da pesquisa qualitativa. Teorias e abordagens. Porto Alegre, Artmed, 2006, pp.345-362.

Must identity movements self-destruct? A queer dilemma. Social Problems, 42, 3, 1995, pp.390-407.

GARFINKEL, Harold. Studies in ethnomethodology. Cambridge, UK, Polity Press, 1967.

GREEN, James, Além do carnaval. A homossexualidade masculina no Brasil do século XX. São Paulo, Editora Unesp, 2000.

GofFMAn, Erwin. Estigma. Rio de Janeiro, Zahar, 1975 [1963].

GUIMARÃES, Carmen Dora. O homossexual visto por entendidos. Rio de Janeiro, Garamond, 2004.

HeIlboRn, Maria Luiza. Dois é par. Gênero e identidade sexual em contexto igualitário. Rio de Janeiro, Garamond, 2004.

. "Ser ou estar homossexual: dilemas de construção de identidade social". In: PARKER, Richard e BARBOSA, Regina Maria. (orgs.) Sexualidades brasileiras. Rio de Janeiro, Relume Dumará, 1996, pp.136-145.

HUMPHREYS, Laud. Tearoom trade. Impersonal sex on public places. Chicago, Aldine, 1970.

IRVINE, Janice. The sociologist as voyeur: social theory and sexuality research, 1910-1978. Qualitative Sociology (26), 4, 2003.

JAGOSE, Annamarie. Queer theory. An introduction. New York University Press, 1996.

KulICK, Don. Travesti. Sex, gender and culture among Brazilian transgendered prostitutes. Chicago, The University of Chicago Press, 1998.

LANDES, Ruth. A cidade das mulheres. Rio de Janeiro, UFRJ, 2002 [1947]. 
Sexualidade, cultura e política

LOBERT, Rosemary. A palavra mágica Dzi: uma resposta difícil de perguntar. Dissertação de Mestrado em Antropologia Social. Campinas, Unicamp, 1979.

MACRAE, Edward. A construção da igualdade. Identidade sexual e política no Brasil da "abertura". Campinas, Ed. da Unicamp, 1990.

MARSHALL, John. Pansies, perverts and macho-men: changing conceptions of male homosexuality. In: PlumMER, Ken. (org.) The making of the modern homosexual. Londres, Hutchinson, 1981.

McIntosh, Mary. The homosexual role. Social Problems (16), 1968, pp.182-192.

MotT, Luiz. A cena gay de Salvador em tempos de Aids. Salvador, Editora do Grupo Gay da Bahia, 2000.

MoutinHo, Laura. Razão, "cor" e desejo. São Paulo, Editora Unesp, 2004.

MURRAY, Steven. The institutional elaboration of a quasi-ethnic community. International Review of Modern Sociology (9), 1979, pp.165-177.

PARKER, Richard. Beneath the Equator. Cultures of desire, male homosexuality and emerging gay communities in Brazil. New York/London, Routledge, 1999 [Trad. Bras.: Abaixo do Equador. Culturas do desejo, homossexualidade masculina e comunidade gay no Brasil. Rio de Janeiro, Record, 2002].

Perlongher, Nestor. O negócio do michê. A prostituição viril. São Paulo, Brasiliense, 1987.

PLUMMER, Ken. Queers, bodies and postmodern sexualities: a note on revisiting the "sexual" in symbolic interactionism. Qualitative Sociology (26), 4, 2003. Routledge, 1975.

REISS JR., Albert. The social integration of queers and peers. In: GAGNON, John e SImON, William (orgs.) Sexual deviance. Nova York, Harper \& Row, 1967, pp.197-228.

RORTY, Richard. Philosophy and the mirror of nature. Princeton. Princeton University Press, 1979. 
Sérgio Carrara e Júlio Simões

RUBIN, Gayle. Studying sexual subcultures: excavating the ethnography of gay communities in Urban North America. In: LEWIN, Ellen e LEAP, William. (orgs.) Out in theory. The emergence of lesbian and gay anthropology. Chicago, University of Illinois Press, 2002, pp.17-68.

SEIDMAN, Steven. Introduction. In: Queer theory/ Sociology. Cambridge, MA, Blackwell, 1996.

SIMÕES, Júlio Assis. Homossexualidade masculina e curso da vida: pensando idades e identidades sexuais. In: PISCITELLI, A.; GREGORI, M. F.; CARRARA, S. (orgs.) Sexualidade e saberes: convenções $e$ fronteiras. Rio de Janeiro, Garamond, 2004.

VANCE, Carole. A antropologia redescobre a sexualidade. Physis (5), 1995.

VeYne, Paul. A homossexualidade em Roma. In: ARIÉs, Philippe e BEJIN, André. (orgs.) Sexualidades Ocidentais. São Paulo, Brasiliense, 1985.

WEEKS, Jeffrey. The "Homosexual role" after 30 years: An appreciation of the work of Mary McIntosh. Sexualities (1), 1998, pp.131-152.

Coming out. Homosexual politics in Britain from the nineteenth century to the present. Londres, Quartet Books, 1977. 